\title{
Exploring physiological and genetic variation of digital cushion thickness in Holstein and Jersey cows and bulls
}

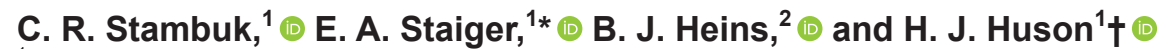 \\ ${ }^{1}$ Department of Animal Science, Cornell University, Ithaca, NY 14853 \\ ${ }^{2}$ Department of Animal Science, University of Minnesota, St. Paul 55108
}

\begin{abstract}
The objectives of our study were to expand phenotypic characterization of digital cushion thickness (DCT) to the Jersey breed and include mature bulls and to identify breed-specific quantitative trait loci (QTL) for DCT within the Jersey or Holstein breeds and common QTL across breeds and sexes to better understand biological regulation and guide future use of marker-assisted selection. In a cohort of 698 cows and 85 bulls (Holstein and Jersey) from 8 farms in New York State, data were collected on DCT, body condition score (BCS), withers height, and sacral height. All animals underwent sonographic examination of the digital cushion evaluated at the sole ulcer site for the right front and hind feet. Linear mixed models were conducted on DCT separately for cows and bulls with fixed effects of time point, breed, age, digit, and BCS group. The models included random effects to control for the random subset of animals per farm, repeated measures, and multiple measurements from each animal. The phenotypic results indicated that DCT varied by time point, breed, age, digit, and BCS group for cows and by breed, age, digit, and BCS group for bulls. For the genotypic study, 616 cow DNA samples were genotyped on the Illumina BovineHD 777K BeadChip (Illumina Inc., San Diego, CA), whereas 76 bull DNA samples were genotyped on different platforms ranging from $5 \mathrm{~K}$ to $150 \mathrm{~K}$. Multiple genome-wide association studies were conducted to highlight pertinent phenotyping parameters and genetic markers for genomic selection. Data were separated into 8 data sets based on different combinations of breed and sex. Each data set was assessed for quality of markers and samples before conducting genome-wide association studies for DCT, testing the inheritance models and genetic variation of
\end{abstract}

Received January 30, 2020.

Accepted May 15, 2020.

*Current address: Department of Animal Sciences, Auburn University, 110 Upchurch Hall, Auburn, AL 36849.

†Corresponding author: hjh3@cornell.edu digit, foot, and average thickness. Ten markers passed the Bonferroni correction threshold and 9 passed false discovery rate from 10 genome-wide association studies using a combination of the covariates breed, sex, genotyping batch plate, age, BCS, withers height, and sacral height. Of the 43 candidate genes, 8 novel biologically plausible genes were identified on Bos taurus autosomes 3, 4, 7, and 9: SFRS18 and LRRFIP1 function in fat deposition, whereas AHR, BZW2, EFNA5, USP45, and $V A V 3$ effect bone growth, and $S O S T D C 1$ is related to epidermal keratinocyte function. The genetic markers associated with DCT in this study were explored for variation between cows and bulls within and across breeds for their potential use in marker-assisted selection.

Key words: claw horn disruption lesion, digital cushion, gene, lameness, marker

\section{INTRODUCTION}

The digital cushion is a complex structure composed mostly of adipose and connective tissue that is crucial in dampening compression of the corium tissue that produces sole horn under the distal phalanx (Lischer et al., 2002; Räber et al., 2004; Shearer et al., 2015). Most of the digital cushion lies behind the navicular bone in the heel area; only $10 \%$ extends forward beneath the distal phalanx (Mülling and Greenough, 2006). Digital cushion thickness (DCT) at the typical sole ulcer site beneath the flexor tuberosity of the distal phalanx has been determined to be a strong predictor of lameness and claw horn disruption lesions (CHDL; sole ulcers and white line disease; Bicalho et al., 2009; Newsome et al., 2017a,b; Stambuk et al., 2019). Claw horn disruption lesions are the most prevalent noninfectious claw disorders associated with lameness and pain (Murray et al., 1996; Oikonomou et al., 2013).

Identifying QTL associated with DCT provides an indirect means to select animals for reduced presence of CHDL and lameness. Digital cushion thickness was previously determined to be moderately heritable (0.32) and to have a negative genetic correlation with CHDL 
$(-0.60 \pm 0.29$; Oikonomou et al., 2014; Stambuk et al., 2020). Heritability estimates for CHDL and lameness according to visual locomotion were low and ranged from 0.01 to 0.12 and from 0.07 to 0.10 , respectively (Sprecher et al., 1997; Heringstad et al., 2018). The presence of CHDL and lameness according to visual locomotion had a moderate phenotypic correlation of 0.49 (Oikonomou et al., 2014).

Thus far, DCT has been characterized in Holstein cows, Brown Swiss cows, Simmental-Red Holstein crossbred cows, and Brown Swiss-Ayrshire crossbred cows. However, DCT has not been compared across breeds in these studies (Räber et al., 2004; Bicalho et al., 2009; Iqbal et al., 2016; Newsome et al., 2017a,b). Similarly, Gard et al. (2015) distinguished the total digital cushion volume and surface area in Jersey and Holstein bull calves but did not evaluate bulls older than 6 mo or Jersey cows. Therefore, the objectives of our study were (1) to examine influences of breed on DCT in cows and bulls, and (2) to identify QTL associated with DCT in Holstein and Jersey cows and bulls. This approach would allow for improved understanding of the biological regulation of DCT within and across breed and sex and inform strategies for implementing marker-assisted selection for DCT to reduce lameness.

\section{MATERIALS AND METHODS}

Approval from the Cornell University Institutional Animal Care and Use Committee (Protocol \#20140121) and signed owner consent were obtained before commencement of the study.

\section{Cows}

Cow data were collected from 7 commercial dairy farms (5 Holstein farms and 2 Jersey farms) from October 13, 2015, to October 26, 2017, in New York State. The farms were selected based on the willingness of managers to accommodate the study and because of easy access to cows, hoof trimmers, and cattle chutes. The total number of cows on farm ranged from 150 to 4,400 cows. The cows were milked 2 to 3 times a day and walked a distance of 3.5 to $379 \mathrm{~m}$ to the milking parlor every milking. Cow milk production ranged 28 to $42 \mathrm{~kg}$ of milk per cow per day. All cows were group housed in freestall pens with bedding that included paper fiber, sand, sawdust on mattresses, or dried manure solids. All cows were trimmed by a hoof trimmer on a routine schedule, and all lame cows were treated when identified as lame by employees.

A total of 502 Holstein cows and 196 Jersey cows were enrolled in a prospective cohort study where DCT measurements were evaluated at 2 time points based on a combination of time periods of thickest and thinnest DCT and the trimming schedule of the farm (Stambuk et al., 2019). The first measurement was $<137 \mathrm{~d}$ prepartum (DPP) when cows were near or in the dry period before calving. The mean (SD) of the measurement was 46 (25) DPP. The large variation in DPP was due to differences in management practices and trimming schedules. The second measurement occurred mid lactation from 86 to 130 DIM, with a mean (SD) of 107 (8) DIM, when DCT was reported to be thinnest and coincided with routine hoof trimming schedules to minimize impact on the cows and farm management (Bicalho et al., 2009; Stambuk et al., 2019).

Hoof trimming was completed by contracted professionals or trained farm employees, and cows were restrained for hoof trimming. Cows on 4 farms were trimmed on a standing chute; 3 farms used an Appleton Steel Trimming Chute (Appleton Steel, Appleton, WI) and 1 farm used a Comfort Chute H-series (Comfort Hoof Care, Baraboo, WI). Three farms trimmed cows on a layover Riley Built trailer model hoof trimming chute (Riley Built, Lubbock, TX).

At each measurement, a single trained researcher collected a BCS, using a 1 to 5 scale with quarter-point increments, as described by Edmonson et al. (1989). Withers height and sacral height were measured at the beginning of the study. Withers height was defined as the distance from the floor to the withers, and sacral height was defined as the distance from the floor to the dorsal aspect of the caudal sacral joint. Age, DIM at each measurement event, and parturition date for the cows were obtained from the farm management software (DairyComp 305; Valley Agricultural Software, Tulare, CA). All cows underwent digital sonographic B-mode examination with an Aquila Vet ultrasound machine (Esaote Europe BV, Maastricht, the Netherlands), following the protocol described in Stambuk et al. (2019). Immediately after trimming, sonograms of the 4 right digits were evaluated. This study measured DCT at the typical sole ulcer site beneath the flexor tuberosity of the distal phalanx.

Before any statistical analysis, 10 cows were excluded based on sampling outside the targeted time points. A total of 688 cows, consisting of 496 Holstein cows and 192 Jersey cows were used in the statistical analysis. The variables of age and BCS were categorized into terciles based on the given cow data set for interpretation of the statistical results. Cows were categorized by age into $<3 \mathrm{yr}$ old, 3 to $4 \mathrm{yr}$ old, and $>4 \mathrm{yr}$ old. Body condition scores were categorized into BCS groups (BCSG), where cows were in the thin group if BCS $<3$, average group if BCS was 3 to 3.25 , and fat group if 
BCS $>3.25$. The variable digit (DGT) represented the specific hoof digits and was categorized as front medial $(\mathbf{F M})$, front lateral $(\mathbf{F L})$, hind medial $(\mathbf{H M})$, and hind lateral (HL) digits.

For statistical analysis of cows, the model formula was

$$
\begin{aligned}
Y_{i j k l m n o}= & \mu+B_{i}+A_{j}+T_{k}+S_{l}+D_{m} \\
& +F_{n}+C_{o}+e_{i j k l m n o},
\end{aligned}
$$

where $Y_{i j k l m n o}$ are the observed values for DCT, $\mu$ is the overall population mean, $B_{i}$ is the fixed effect of breed (Holstein or Jersey), $A_{j}$ is the fixed effect of age, $T_{k}$ is the fixed effect of time point $(<137 \mathrm{DPP}$ or 86 to 127 DIM), $S_{l}$ is the fixed effect of BCSG, $D_{m}$ is the fixed effect of DGT, $F_{n}$ is the random effect of farm, $C_{o}$ is the random effect of cow nested within farm with repeated measures of DGT, and $e_{i j k l m n o}$ is the random residual error. The compound symmetry covariance structure was used because it resulted in the lowest Akaike information criterion for repeated measures (Littell et al., 1998). The MIXED procedure of SAS (version 9.4; SAS Institute Inc., Cary, NC) was used to obtain solutions and conduct the ANOVA. Assumptions of homogeneity, normality, and independence of the residuals for the mixed model were obtained. Pairwise mean comparisons evaluated significant effects in all models, and $P$-values were adjusted for multiple comparisons using the Tukey-Kramer method. All treatment results were reported as LSM, with significance declared at $P<$ 0.05 .

\section{Bulls}

Bull data were collected from 1 Genex facility from March 14, 2018, to July 19, 2018, located in Ithaca, New York. The bull facility had 189 bulls in 2 buildings. The bulls were housed indoors in separate stalls with rubber mats and sawdust; their stalls were cleaned with fresh sawdust added daily. On average, bulls walked 55 $\mathrm{m}$ and $82 \mathrm{~m}$ to the semen collection area in the first and second buildings, respectively. Bull semen collection depended on the priority of the bull and averaged 4 times a week.

A total of 85 bulls were enrolled in a cross-sectional study where DCT was measured 1 time when the bulls were due for their routine hoof trimming. For the bull data, 73 were Holstein bulls and 12 were Jersey bulls. Data collected included DCT measurements of the 4 right digits, BCS, withers height and sacral height. The manager provided the birth dates for the bulls. Hoof trimming was completed by 2 trained employees where one trimmed the front feet and the other trimmed the hind feet. Each bull was walked to the trim chute separately. Bulls were restrained for hoof trimming using an Appleton Steel Trimming Chute (Appleton Steel). All bulls underwent digital sonographic B-mode examination with an Aquila Vet ultrasound machine (Esaote Europe BV) following the protocol described in Stambuk et al. (2019). Immediately after trimming, the DCT of the 4 right digits was measured at the typical sole ulcer site beneath the flexor tuberosity of the distal phalanx from the sonogram.

Before any statistical analysis, the age and BCS variables were categorized into terciles based on the given bull data set. Bulls were categorized by age into $<2$ yr old, 2 to 3 yr old, and $>3$ yr old. Body condition score groups were defined as thin if $\mathrm{BCS}<2.75$, average if BCS was 2.75 to 3.25 , and fat if BCS $>3.25$. The variable DGT represented the specific hoof digits as denoted in the cows and was categorized as FM, FL, HM, and HL.

For statistical analysis of bulls, the model formula was

$$
Y_{i j k l m}=\mu+B_{i}+A_{j}+S_{k}+D_{l}+C_{m}+e_{i j k l m}
$$

where $Y_{i j k l m}$ are the observed values for DCT, $\mu$ is the overall population mean, $B_{i}$ is the fixed effect of breed (Holstein or Jersey), $A_{j}$ is the fixed effect of age, $S_{k}$ is the fixed effect of BCSG, $D_{l}$ is the fixed effect of DGT, $C_{m}$ is the random effect of bull with repeated measures of DGT, and $e_{i j k l m}$ is the random residual error. The compound symmetry covariance structure was used because it resulted in the lowest Akaike information criterion for repeated measures (Littell et al., 1998). The MIXED procedure of SAS (version 9.4; SAS Institute Inc.) was used to obtain solutions and conduct the ANOVA. Pairwise mean comparisons evaluated significant effects in all models and $P$-values were adjusted for multiple comparisons using the Tukey-Kramer method. All treatment results were reported as LSM, with significance declared at $P<0.05$.

\section{Genotyping and Quality Control}

For subsequent DNA extraction, whole blood (10 $\mathrm{mL}$ ) from cows was obtained via the coccygeal vessels into Vacutainer tubes (Becton, Dickinson, \& Company, Franklin Lakes, NJ) with the anticoagulant $\mathrm{K}_{2}$ EDTA. Genomic DNA was extracted following the Gentra Puregene Blood Kit extraction protocol (Qiagen, Valencia, CA). A total of 616 cow samples were genotyped on the Illumina BovineHD 777K BeadChip (Illumina 
Inc., San Diego, CA) at GeneSeek (Neogen Genomics, Lincoln, NE).

A total of 76 bull genotypes (64 Holstein and 12 Jersey bulls) were provided by Genex. The bulls were genotyped on a variety of SNP panel sizes, ranging from $5 \mathrm{~K}$ to $150 \mathrm{~K}$. The bulls genotyped on lower-density SNP panels restricted the total number of SNP available for genome-wide interrogation in the bull data sets and within-breed data sets. Cow and bull genotypes were not imputed due to lack of a sufficient reference data set.

The data were separated into 8 data sets based on combinations of breed and cows and bulls. All data sets (Table 1) evaluated the same quality assessment of the markers and samples using Golden Helix SVS (version 8.8.3; Golden Helix, Bozeman, MT). Single nucleotide polymorphisms were removed if they had a call rate $<0.90$, a minor allele frequency $<0.03,>2$ alleles, and Hardy-Weinberg equilibrium $P$-value < 0.0001. To evaluate population structure and relatedness, an identity-by-state similarity matrix was used to calculate genome-wide identity-by-descent estimates (Purcell et al., 2007). Samples with a call rate $<0.90$ were removed. One of the samples within a pair with an identity-by-descent estimate $>0.85$, denoting substantial relatedness, was removed.

\section{GWAS}

Digital cushion thickness was defined as the quantitative measurements of each claw $(\mathrm{n}=4)$, the averages of foot $(\mathrm{n}=2)$, and all measurements combined ( $\mathrm{n}$ $=1$ ) to explore relationships between genomic regions related to digit, foot, breed, and cows or bulls. This required multiple association studies to be performed with the intention of providing biological insight into the genetic regulation of DCT related to digit, foot, breed, and sex, the identification of optimal phenotypic parameters for future sampling (i.e., single digit measurement compared with an average measurement), and identification of markers appropriate for within- or across-breed genomic selection schemes. The values for FM, FL, HM, and HL digits were averages from the 2 time points for the cows. The SNP heritability of DCT and power to predict associations between DCT measurements and SNP were determined for the 7 trait definitions of DCT (FM, FL, HM, and HL, front foot, hind foot, and all digits combined) per data set including covariate combinations of breed, sex, genotyping batch plate, age, BCS, withers height, and sacral height with the use of GCTA software (Genome-wide Complex Trait Analysis; Yang et al., 2011). Single nucleotide polymorphism heritability is the proportion of phenotypic variance attributable to the additive effects of a

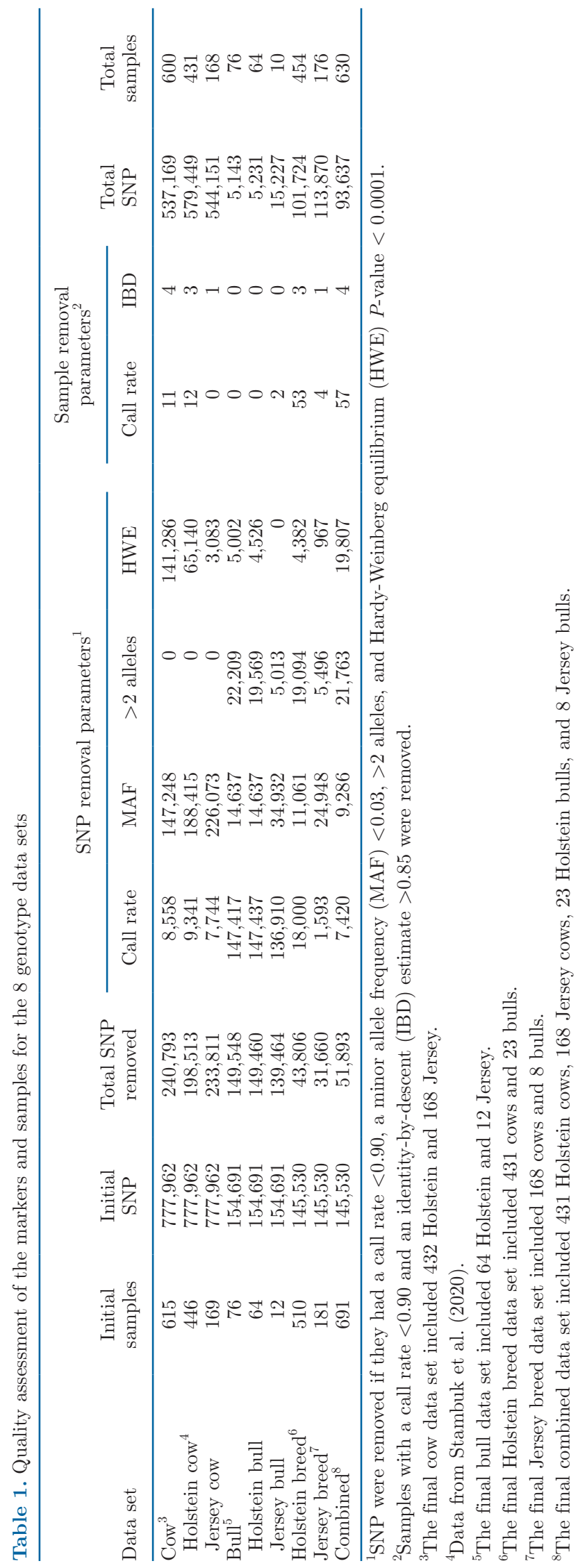


given set of SNPs and is calculated by fitting variance components models with REML estimation (Hou et al., 2019). The SNP heritability and power were calculated with the formula

$$
h^{2}=\sigma_{g}^{2} /\left(\sigma_{g}^{2}+\sigma_{e}^{2}\right)
$$

where $\sigma_{g}^{2}$ is the genetic variance and $\sigma_{e}^{2}$ is the variance due to the environment (Zaitlen and Kraft, 2012). The genetic variance $\left(\sigma_{g}^{2}\right)$ includes additive, dominance, and epistatic effects, which is different from the classical narrow-sense heritability that only includes additive effects. The SNP heritability estimate is determined by the relationship at the causal variants that is predicted by the genetic relationship from the SNP and the variance explained by the SNP (Yang et al., 2011). Statistical power was calculated using the sample size, SNP heritability, type 1 error, and variance of SNP-derived genetic relationships (Visscher et al., 2014).

All 7 trait definitions of DCT (FM, FL, HM, and HL, front foot, hind foot, and all digits combined) were evaluated for power based on each of the 8 data sets (Holstein and Jersey cows, Jersey cows, Holstein and Jersey bulls, Holstein bulls, Jersey bulls, Holstein cows and bulls, Jersey cows and bulls, Holstein and Jersey cows and bulls). If the power was $>0.80$, then the trait was evaluated in GWAS with that data set. Associations were assessed using EMMAX algorithms embedded in Golden Helix SVS software (version 8.8.3; Golden Helix) to correct for population structure and relatedness by including a genomic relationship matrix as a random effect in the models (Kang et al., 2010). Golden Helix SVS software may test for additive, dominance, and recessive hypotheses, and incidence matrices are modified during calculations. The mixed model EMMAX uses the following general equation:

$$
\mathbf{y}=\mathbf{X} \boldsymbol{\beta}+\mathbf{Z u}+\mathbf{e},
$$

where $\mathbf{y}$ is an $n \times 1$ vector of observed phenotypes; $\mathbf{X}$ is an $n \times f$ matrix of fixed effects including mean, SNP, and other covariates; $\boldsymbol{\beta}$ is an $f \times 1$ vector representing coefficient of the fixed effects; $\mathbf{Z}$ is an $n \times t$ matrix relating the instances of the random effect to the phenotypes; $\mathbf{u}$ is the unknown random effect of the mixed model with $\operatorname{Var}(u)=\sigma_{g}^{2} \mathbf{K}$, where $\mathbf{K}$ is the kinship matrix inferred from the genotype, and $\mathbf{e}$ is an $n \times n$ matrix of residual effect that cannot be explained by the variables in the model (Kang et al., 2008). For the EMMAX mixed model, the effect for each SNP is small; thus, the variance components are calculated for the whole GWAS analysis.

Association studies with a combination of the covariates breed, sex, genotyping batch plate, age, BCS, withers height, and sacral height were considered in additive, dominant, and recessive inheritance models, which also informed the appropriateness of marker results for use in genomic selection schemes. The covariate of farm was investigated but could not be included in the cow data sets with genotyping batch plate because they were highly correlated. Genotyping batch plate accounts for the differences based on genotyping batch as well as farm because one batch contained samples from 1 farm, whereas the other batch included samples from the other 4 farms. Farm could not be included with the covariates sex or breed because all bulls were from the same farm. Body condition score for the cows was an average between the 2 time points to have one BCS covariate similar to the bulls for analysis. Withers and sacral heights were continuous measurements.

Quantile-quantile plots and pseudo-lambda values were used to determine the model of best fit for each trait and inheritance model. Either a Bonferroni-adjusted $P$-value or false discovery rate (FDR)-adjusted $P$-value $<0.05$ distinguished SNP significantly associated with DCT. Candidate regions were examined for putative candidate genes based on the linkage disequilibrium (LD) structure or a $1-\mathrm{Mb}$ window centered on the significantly associated SNP if LD was not present using the Bos taurus ARS-UCD1.2 assembly in the NCBI Genome Data Viewer (https://www.ncbi.nlm .nih.gov/genome/82).

\section{RESULTS}

\section{Linear Mixed Models of DCT}

Table 2 shows descriptive statistics separated by cows and bulls for all DCT measurements, age, BCS, withers height, and sacral height. For the cow data set, DCT varied by breed, age, time point, DGT, and BCSG (Table 3). Holstein cows had thicker DCT than Jersey cows $(P<0.001)$. Cows $\geq 3$ yr old had thicker DCT than younger cows $(P<0.001)$. Cows had thicker DCT before calving than during mid lactation $(P<$ 0.001). The FM digit had the thickest DCT, whereas the HM digit had the thinnest $(P<0.05)$. Digital cushion thickness differed based on BCSG; cows with $>3.25$ BCS had thicker DCT than those with lower BCS $(P$ $<0.001$ ).

For the bull data set, DCT varied by breed, age, DGT, and BCSG (Table 4). Holstein bulls had thicker DCT than Jersey bulls $(P=0.003)$. Young bulls $\leq 3$ 
Table 2. Descriptive statistics for continuous variables separated by breed and sex

\begin{tabular}{|c|c|c|c|c|c|c|}
\hline Variable & \multicolumn{3}{|c|}{ Holstein } & \multicolumn{3}{|c|}{ Jersey } \\
\hline \multicolumn{7}{|l|}{ Cows } \\
\hline Age $(y r)$ & $3.71 \pm 1.44$ & 2 & 10 & $3.99 \pm 1.28$ & 2 & 8 \\
\hline BCS & $3.00 \pm 0.58$ & 1.00 & 4.75 & $3.01 \pm 0.63$ & 1.25 & 4.75 \\
\hline Withers height $^{2}(\mathrm{~cm})$ & $145 \pm 5.92$ & 129 & 160 & $126 \pm 3.26$ & 117 & 135 \\
\hline \multicolumn{7}{|l|}{ Bulls } \\
\hline DCT (cm) & $0.87 \pm 0.20$ & 0.42 & 1.49 & $0.75 \pm 0.21$ & 0.42 & 1.61 \\
\hline Age (yr) & $3.03 \pm 1.67$ & 1 & 7 & $2.17 \pm 1.15$ & 1 & 5 \\
\hline $\mathrm{BCS}$ & $2.74 \pm 0.63$ & 1.5 & 3.75 & $3.33 \pm 0.43$ & 2.75 & 4 \\
\hline Withers height (cm) & $156 \pm 10.46$ & 128 & 177 & $133 \pm 6.87$ & 122 & 148 \\
\hline Sacral height (cm) & $157 \pm 7.50$ & 139 & 175 & $133 \pm 5.45$ & 124 & 141 \\
\hline
\end{tabular}

${ }^{1} \mathrm{DCT}=$ digital cushion thickness.

${ }^{2}$ Assessed as the distance from the floor to the withers.

${ }^{3}$ Assessed as the distance from the floor to the dorsal aspect of the caudal sacral joint.

yr old had thinner DCT than older bulls $(P<0.02)$. The front digits were thicker than either hind digit, with HM being the thinnest $(P<0.05)$. Digital cushion thickness differed based on BCSG such that bulls in the thin group had thinner DCT than those in the thick group $(P=0.03)$.

\section{GWAS}

Multiple GWAS were performed to identify genetic variation related to breed, sex, and type of phenotypic

Table 3. Least squares means $(\mathrm{LSM}) \pm$ SEM for digital cushion thickness for cows

\begin{tabular}{llll}
\hline Variable & Category & $\begin{array}{c}\text { LSM } \\
(\mathrm{cm} \pm \mathrm{SEM})\end{array}$ & $P$-value \\
\hline Breed & Holstein & $1.17^{\mathrm{a}} \pm 0.05$ & $<0.001$ \\
& Jersey & $1.01^{\mathrm{b}} \pm 0.06$ & \\
Age (yr) & $<3$ & $1.03^{\mathrm{b}} \pm 0.05$ & $<0.001$ \\
& 3 to 4 & $1.11^{\mathrm{a}} \pm 0.05$ & \\
& $>4$ & $1.12^{\mathrm{a}} \pm 0.05$ & \\
Time point & & $1.13^{\mathrm{a}} \pm 0.05$ & \\
& $<137$ DPP & $1.04^{\mathrm{b}} \pm 0.05$ & \\
Digit & 86 to 127 DIM & $1.16^{\mathrm{a}} \pm 0.05$ & \\
& & $1.10^{\mathrm{b}} \pm 0.05$ & \\
& Front medial & $1.02^{\mathrm{c}} \pm 0.05$ & \\
& Front lateral & $1.08^{\mathrm{b}} \pm 0.05$ & \\
BCS group & Hind medial & & $<0.001$ \\
& Hind lateral & $1.07^{\mathrm{b}} \pm 0.05$ & \\
& Thin $(<3)^{2}$ & $1.07^{\mathrm{b}} \pm 0.05$ & \\
& Average $(3-3.25)$ & $1.11^{\mathrm{a}} \pm 0.05$ & \\
\hline
\end{tabular}

\footnotetext{
${ }^{\mathrm{a}-\mathrm{c}}$ Within a variable, category LSM with different superscripts are different at Tukey-Kramer adjusted $P<0.05$.

${ }^{1} \mathrm{DPP}=$ days prepartum.

${ }^{2}$ Category thresholds are denoted in parentheses.
}

measure of DCT (digit, foot, average). Genome-wide association studies were not evaluated on the combined bull data set nor on the Holstein bull or Jersey bull data sets because either they did not have enough animals to calculate heritability or the power to predict an association was $<0.80$.

\section{Holstein and Jersey Cows}

All 7 definitions of DCT evaluating the digit, foot, and average DCT of all measures had sufficient heritability and power to be evaluated in a GWAS combining Holstein and Jersey cows. Six of the 7 GWAS models did not provide significant results. The dominant

Table 4. Least squares means (LSM) \pm SEM for digital cushion thickness for bulls

\begin{tabular}{llrr}
\hline Variable & Category & $\begin{array}{c}\text { LSM } \\
(\mathrm{cm} \pm \text { SEM })\end{array}$ & $P$-value \\
\hline Breed & Holstein & $0.87^{\mathrm{a}} \pm 0.02$ & 0.003 \\
& Jersey & $0.75^{\mathrm{b}} \pm 0.04$ & \\
Age $(\mathrm{yr})$ & $<2$ & $0.73^{\mathrm{b}} \pm 0.03$ & 0.002 \\
& 2 to 3 & $0.79^{\mathrm{b}} \pm 0.03$ & \\
& $>3$ & $0.91^{\mathrm{a}} \pm 0.03$ & \\
Digit & Front medial & $0.92^{\mathrm{a}} \pm 0.02$ & \\
& Front lateral & $0.86^{\mathrm{a}} \pm 0.02$ & \\
& Hind medial & $0.67^{\mathrm{c}} \pm 0.02$ & \\
& Hind lateral & $0.78^{\mathrm{b}} \pm 0.02$ & \\
& & & \\
BCS group & Thin $(<2.75)^{1}$ & $0.75^{\mathrm{c}} \pm 0.04$ & \\
& Average $(2.75-3.25)$ & $0.81^{\mathrm{bc}} \pm 0.03$ & \\
& Thick $(>3.25)$ & $0.87^{\mathrm{ab}} \pm 0.03$ & \\
\hline
\end{tabular}

${ }^{a-c}$ Within a variable, category LSM with different superscripts are different at Tukey-Kramer adjusted $P<0.05$.

${ }^{1}$ Category thresholds are denoted in parentheses. 
inheritance model GWAS of the average DCT of all measurements identified 2 SNP on BTA3 (Appendix Figure A1).

\section{Jersey Cows}

Five definitions of DCT for the Jersey cow data set did not have enough power to conduct a GWAS. The recessive inheritance model GWAS for DCT of the HL digit identified 274 markers associated with DCT based on FDR. However, these markers were not investigated for candidate genes because of early deviation and later migration back toward the null on the quantile-quantile plot and the possibility of false positives (Appendix Figure A2).

\section{Holstein Cows and Bulls}

All 7 definitions of DCT had sufficient estimated heritability and power to predict an association to be evaluated in GWAS combining Holstein cows and bulls. Three of the 7 GWAS models did not provide significant results. The recessive inheritance model GWAS for DCT of the FM digit identified BovineHD0700031927 on BTA7. The recessive inheritance model GWAS of the average DCT of the front foot identified BovineHD0400007408 on BTA4 and BovineHD1400023369 on BTA14. The additive inheritance model GWAS of the average DCT of the hind foot identified BovineHD2700001206, BovineHD2700001209, and BovineHD2700001220 on BTA27. The additive inheritance model GWAS of the average DCT of all measurements identified BovineHD2700001198 on BTA27 (Appendix Figure A3).

\section{Jersey Cows and Bulls}

Two definitions of DCT for the Jersey data set including cows and bulls did not have enough power to conduct a GWAS. Two of the 5 remaining GWAS models did not provide significant results. The recessive inheritance model GWAS of DCT of the HL digit identified BovineHD0300034341, ARS-BFGL-NGS-58312, BTA69789-no-rs on BTA3, BovineHD0700031919 on BTA7, and BovineHD0900014057 and BovineHD0900014062 on BTA9. The additive inheritance model GWAS of the average DCT of the hind foot identified Hapmap41614BTA- 67626 on BTA3. The recessive inheritance model GWAS of the average DCT of all measurements identified BovineHD0300034341 on BTA3 (Appendix Figure A4). BovineHD0300034341 passed the Bonferroni cutoff in the GWAS of DCT of the HL digit and passed FDR in the GWAS of the average DCT of all measurements.

\section{Holstein and Jersey Cows and Bulls}

All 7 definitions of DCT had enough heritability and power to be evaluated in a GWAS combining bulls and cows of both breeds. However, 5 of the 7 GWAS models did not provide significant results. The additive inheritance model GWAS of DCT of the HL digit identified BovineHD4100007739 on BTA9 associated with DCT. The additive inheritance model GWAS of the average DCT of the front foot identified BovineHD3000041411 and BovineHD3000041398 on the X chromosome associated with DCT (Appendix Figure A5).

The range of pseudo-lambda values for the 10 models from all data sets with significant SNP was between 1.0 and 1.02, indicating limited stratification due to substructure. The 10 SNP that passed the Bonferroni cutoff had adjusted $P$-values that ranged from 0.01 to 0.04. The 10 additional SNP that only passed FDR had an adjusted $P$-value range of 0.03 to 0.05 (Table 5). BovineHD0300034341 on BTA3 passed the Bonferroni cutoff for the recessive inheritance model of the HL digit and passed FDR for the recessive inheritance model of the average of all DCT measurements in the Jersey data set. The SNP heritability estimates for the 28 DCT models with sufficient power ranged from 0.20 to 0.76 , with an average of $0.52 \pm 0.15$, whereas the SNP heritability of DCT from the 10 models with significant SNP ranged from 0.33 to 0.76 , with an average of $0.58 \pm 0.17$. The average genetic variation of DCT from the 10 models with significant SNP ranged from 0.006 to 0.052 , with a mean of 0.023 (Table 6).

The LD structure was evaluated for 19 markers that surpassed the Bonferroni-adjusted cutoff or FDR. Fourteen of the 19 markers were in blocks of LD (Appendix Figures A6 and A7). Forty-three candidate genes were identified in the NCBI Genome Data Viewer, either within the block of $\mathrm{LD}$ if $\mathrm{R}^{2}$ was $>0.80$ or within a $1-\mathrm{Mb}$ window centered on the significantly associated SNP (Table 7). Seven of the 19 markers resided within genes: Hapmap41614-BTA-67626 within NTNG1 (netrin G1); BovineHD0300034341, ARS-BFGL-NGS-58312, and BTA-69789-no-rs within LRRFIP1 (LRR binding FLII interacting protein 1); BovineHD0900014057 within SFRS18 (arginine/serine-rich protein PNISR); BovineHD0900014062 within PNISR (PNN interacting serine and arginine rich protein); and BovineHD3000041411 and BovineHD3000041398 within LOC100851938 (histone-lysine $N$-methyltransferase PRDM9-like). Eight of the 43 candidate genes had functional annotations likely related to the digital cushion; SFRS18 and LRRFIP1 function in fat tissue deposition. AHR (aryl hydrocarbon receptor), BZW2 (basic leucine zipper and W2 domains 2), EFNA5 (ephrin A5), USP 45 


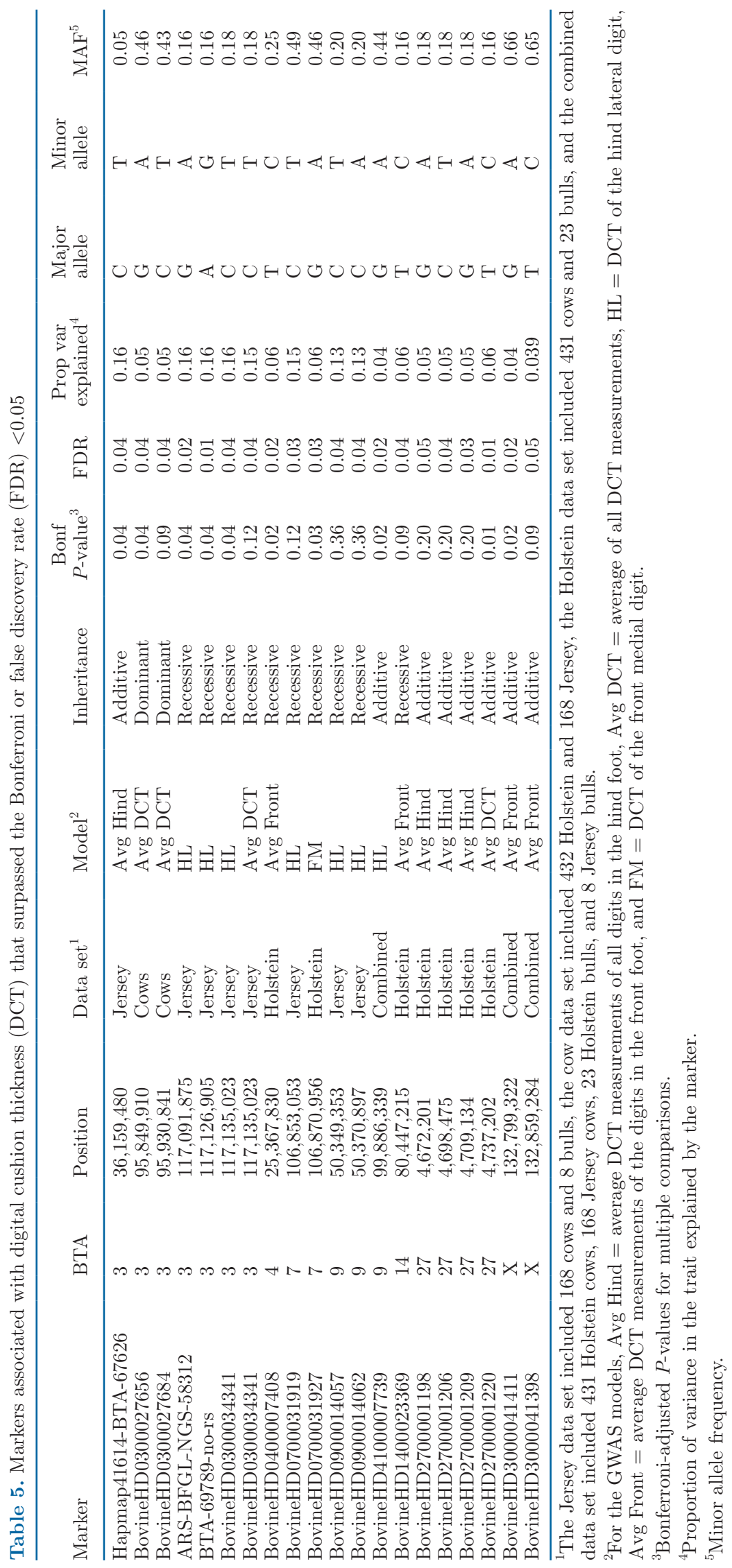


Table 6. Single nucleotide polymorphism heritability $\left(h^{2}\right) \pm$ SE of digital cushion thickness from the 10 GWAS models with markers that surpassed the Bonferroni or false discovery rate $<0.05$

\begin{tabular}{llccc}
\hline Data set $^{1}$ & Model $^{2}$ & $\mathrm{~h}^{2}$ & $\mathrm{SE}$ & $\mathrm{V}(\mathrm{g})^{3}$ \\
\hline Cows & Avg DCT & 0.43 & 0.12 & 0.009 \\
Combined & HL & 0.69 & 0.10 & 0.034 \\
& Avg Front & 0.64 & 0.10 & 0.024 \\
Holstein & FM & 0.74 & 0.12 & 0.052 \\
& Avg Front & 0.70 & 0.12 & 0.030 \\
& Avg Hind & 0.72 & 0.12 & 0.026 \\
\multirow{3}{*}{ Jersey } & Avg DCT & 0.76 & 0.12 & 0.025 \\
& HL & 0.33 & 0.28 & 0.010 \\
& Avg Hind & 0.45 & 0.29 & 0.010 \\
& Avg DCT & 0.34 & 0.29 & 0.006 \\
\hline
\end{tabular}

${ }^{1}$ The cow data set included 432 Holstein and 168 Jersey, the combined data set included 431 Holstein cows, 168 Jersey cows, 23 Holstein bulls, and 8 Jersey bulls, the Holstein data set included 431 cows and 23 bulls, and the Jersey data set included 168 cows and 8 bulls.

${ }^{2}$ For the GWAS models, Avg DCT = average digital cushion thickness $(\mathrm{DCT})$ measurements of all digits, $\mathrm{HL}=\mathrm{DCT}$ of the hind lateral digit, Avg Front $=$ average DCT measurements of the digits in the front foot, $\mathrm{FM}=\mathrm{DCT}$ of the front medial digit, and Avg Hind = average DCT measurements of all digits in the hind foot.

${ }^{3} \mathrm{~V}(\mathrm{~g})=$ genetic variation.

(ubiquitin specific peptidase 45), VAV3 (Vav guanine nucleotide exchange factor 3 ) have functions related to bone growth, whereas SOSTDC1 (sclerostin domain containing 1) is associated with epidermal keratinocyte function.

\section{DISCUSSION}

Digital cushion measurements of Holsteins were thicker than DCT measurements of Jerseys for both cows and bulls. Holsteins have the highest BW of US dairy breeds; therefore, the thicker digital cushion in Holsteins may support hoof integrity for their larger body size (Holstein Association USA, 2019). The HM digit was thinnest for either sex and the FM digit was thickest for cows, consistent with previous cow results (Stambuk et al., 2019). For bulls, both front digits were thicker than either hind digit. Cattle have to bear $60 \%$ of their BW on their forelimbs, meaning there is an unequal distribution of weight, which could cause differences in DCT of the front versus hind digits (Bergsten et al., 2007).

Body condition score group influenced DCT in cows and bulls. Cows with BCS $>3.25$ had thicker DCT than cows with BCS $\leq 3.25$. Similarly, bulls with BCS $>3.25$ had thicker DCT than bulls with $<2.75$ BCS. Differences in BCSG for the bulls could be due to management practices. Thinner bulls tended to be

Table 7. Candidate genes determined from the markers associated with digital cushion thickness that surpassed the Bonferroni or false discovery rate significance of $<0.05$

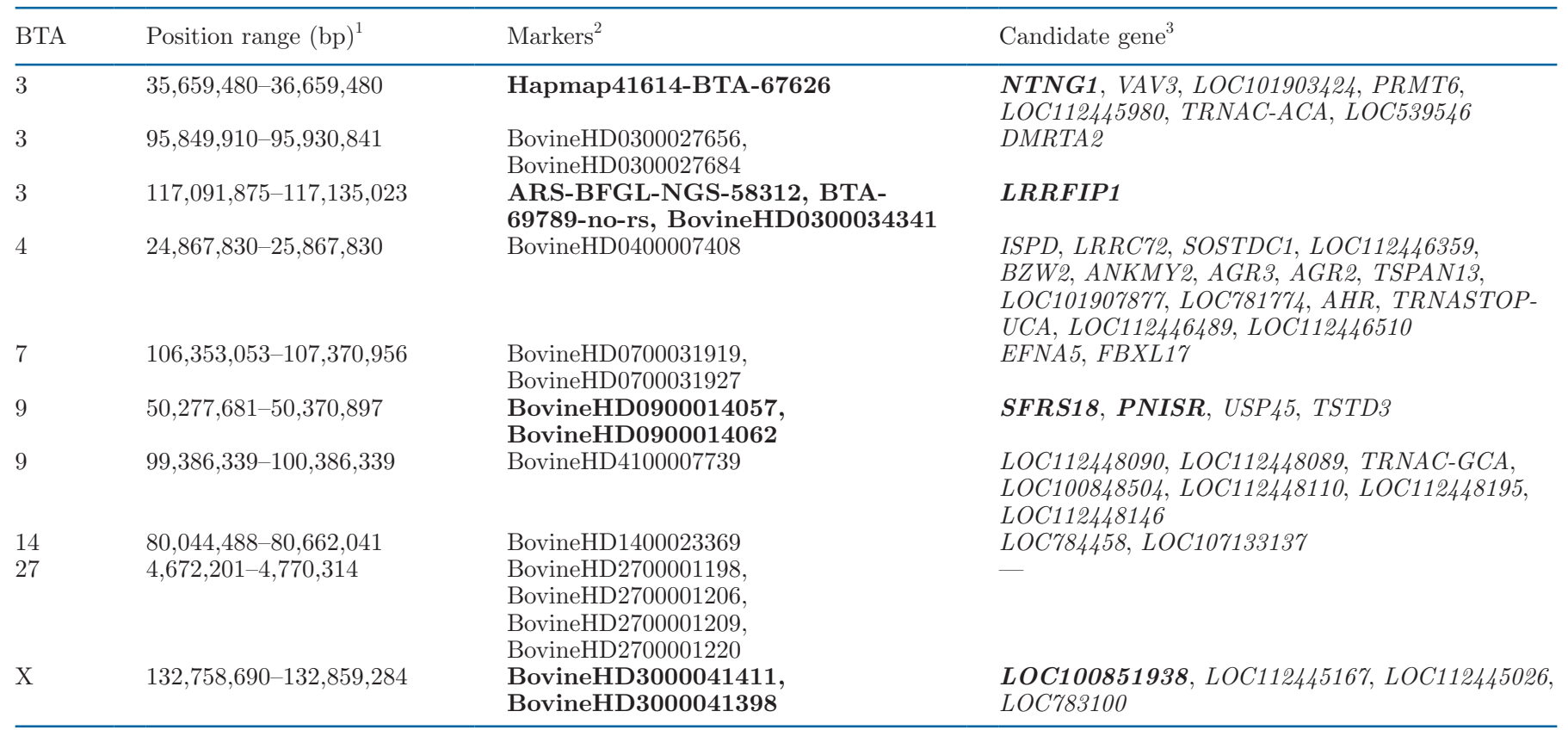

${ }^{1}$ Position determined by blocks of linkage disequilibrium with an $\mathrm{R}^{2}>0.80$ or within 500,000 bp upstream and 500,000 bp downstream of the marker.

${ }^{2}$ The markers are those genotyped within the position range that were determined to be significantly associated with digital cushion thickness. Markers are bolded if they reside within a gene.

${ }^{3}$ Genes are bolded if a marker is annotated within them. 
the older bulls who were handled more often for semen collection, potentially utilizing more body reserves for energy. Younger bulls were handled less often. Previous research reported conflicting results on the relationship between DCT and BCS. Bicalho et al. (2009), Machado et al. (2011), and Stambuk et al. (2020) reported DCT to be positively associated with BCS, increasing as BCS increased because of the added fat reserves. However, Stambuk et al. (2019) and Newsome et al. (2017a) did not find a relationship between BCS and DCT. The contradicting results could be due to sample size and differences in populations, particularly inclusion of multiple breeds and cows and bulls in the current study.

The bulls sampled for this study lived in a facility with different management practices than the cows. All cows were group housed in freestall barns, whereas all bulls were housed in separate stalls. Cow pens were cleaned whenever the cows went to the parlor for milking. The bulls had their stalls cleaned and fresh sawdust added daily. Manure accumulated faster and in greater volume in the freestall barns because of the larger number of animals per pen. Before trimming, the bulls had claws that were drier and showed more natural wear as opposed to the wet, overgrown claws of the cows. The wall horn of bull claws was often longer than the sole horn, illustrating that weight was being sustained on the hoof wall rather than the sole. Observation of variation in facilities and management suggests environmental factors potentially influencing hoof wear that may be contributing to the trend seen in the mean DCT measurements by sex, with cows having a thicker mean DCT and more variation in the measurements than bulls.

Further investigation into the functions of the candidate genes for DCT revealed 8 novel biologically plausible genes related to fat tissue deposition, bone growth, and epidermal keratinocyte function. The current study identified 2 new candidate genes related to fat tissue deposition, SFRS18 (closest SNP = BovineHD0900014057, Bonferroni $P$-value $=0.36, \mathrm{FDR}$ $=0.04$, BTA9:50349353, annotated in SFRS18, Figure A4) and LRRFIP1 (closest SNP = BTA-69789-nors, Bonferroni $P$-value $=0.04, \mathrm{FDR}=0.01, \mathrm{BTA} 3$ : 117126905, 1 of 3 annotated in LRRFIP1, Figure A4), in the GWAS on the hind lateral digit for Jersey. The LRRFIP1 gene was also a candidate for average DCT of all measurements for Jersey. Previous research associated SFRS18 with the regulation of intramuscular fat deposition in pigs, whereas LRRFIP1 was associated with obesity and inflammation in humans (Wang et al., 2009; Plourde et al., 2013). Because the digital cushion consists of mostly adipose tissue, fat tissue accumulation identifies SFRS18 and LRRFIP1 as promising candidate genes (Räber et al., 2004). Inflammation effects of LRRFIP1 could also affect the thickness of the digital cushion in relation to lameness. Newsome et al. (2017a) reported that the thickness of the digital cushion was greater when a sole ulcer was present due to increased inflammation in the underlying tissues. Moreover, LRRFIP1 might have a greater effect on DCT of the HL digit because the lateral claw of the hindlimb bears more weight and incurs more lesions than the medial claws (Toussaint Raven, 1989; Murray et al., 1996; Van der Tol et al., 2002). These 2 genes are in addition to the $M C 4 R$ gene, also related to fat deposition, recently published in relationship to the Holstein cow data set (Stambuk et al., 2020). The $M C 4 R$ gene was identified for the average FM digit and average DCT of the digits in the front foot, which includes the FM digit, which was determined to be thickest for Holstein cows in Stambuk et al. (2020).

Five candidate genes are related to bone formation or resorption depending on expression: $A H R, B Z W 2$, EFNA5, USP 45, and VAV3. The AHR gene is involved in osteoblast and osteoclast differentiation and maturation in bone marrow stem cells from rats and mice (Korkalainen et al., 2009). The BZW2 gene affects osteosarcoma in human cell lines by accelerating bone tumor growth (Cheng et al., 2017). The EFNA5 gene was highly expressed in osteolytic human prostate or breast cancer cells that were inoculated into the bone marrow cavity of the tibial bones of immunocompromised mice (Hensel et al., 2018). Overexpression of USP 45 inhibits osteogenesis or formation of new bone in human patients with glucocorticoid-induced osteonecrosis of the femoral head (Kuang et al., 2019). Deficiency in VAV3 leads to dysfunctional osteoclasts and osteosclerosis or abnormal hardening of bone with increased bone density in mice (Faccio et al., 2005). Similar to these genes, $D L G 2$, related to bone growth, was identified as a candidate gene in GWAS models for the average DCT of time point 1 measurement when the digital cushion was thickest for Holstein cows in Stambuk et al. (2020).

Even though much of the research into these genes is based upon disease association, it is biologically plausible that mutations in any of these genes could affect bone development in the distal phalanx, thereby influencing the thickness of the digital cushion. For instance, Newsome et al. (2016) suggested that bone development on the caudal aspect of the distal phalanx affects CHDL, which is genetically correlated with DCT (Oikonomou et al., 2014). Both AHR (closest SNP = BovineHD0400007408, Bonferroni $P$-value $=0.02$, FDR $=0.02$, BTA4:25367830, Figure A3) and BZW2 (closest SNP $=$ BovineHD0400007408, Bonferroni $P$-value $=0.02, \mathrm{FDR}=0.02, \mathrm{BTA} 4: 25367830$, Figure A3) are 
candidate genes for the average DCT of the digits in the front foot for Holstein, which includes the FM digit that was determined to be thickest for Holstein cows in a previous study (Stambuk et al., 2020) and in both cows and bulls in the current study. The USP 45 gene (closest SNP $=$ BovineHD0900014057, Bonferroni $P$ value $=0.36, \mathrm{FDR}=0.04, \mathrm{BTA} 9: 50349353$, Figure A4) was a candidate for the HL digit, whereas VAV3 (closest $\mathrm{SNP}=$ Hapmap41614-BTA-67626, Bonferroni $P$-value $=0.04, \mathrm{FDR}=0.04, \mathrm{BTA3}: 36159480$, Figure A4) was a candidate for the average DCT of the hind digits in Jersey, which includes the HM digit that was determined to be thinnest for both cows and bulls. The EFNA5 gene (closest SNP = BovineHD0700031919, Bonferroni $P$-value $=0.12, \mathrm{FDR}=0.03, \mathrm{BTA} 7: 106853053$, Figure A4) was a candidate for the FM digit for Holstein, which was thickest for both cows and bulls, and for the HL digit for Jersey. Overall, candidate genes potentially related to bone development were determined in multiple GWAS models for both breed data sets.

The SOSTDC1 gene (closest SNP = BovineHD0400007408, Bonferroni $P$-value $=0.02$, FDR $=$ 0.02, BTA4:25367830, Figure A3) was identified as a candidate for the GWAS on the average DCT of the digits in the front foot for Holstein, which includes the FM digit that was determined to be thickest for both cows and bulls. It was previously associated with epidermal keratinocyte function (Hsieh et al., 2014). The claw horn capsule, including the sole horn that lies beneath the digital cushion, is created by keratinization of living epidermal cells (Mülling et al., 1999). Potentially, mutations in SOSTDC1 could affect the quality and density of the sole horn of the front digits, thus influencing the quality of the sonogram from which the measurement of DCT was determined. The front digits were among the thickest for both cows and bulls; therefore, SOSTDC1 could be contributing to a thicker digital cushion due to healthier horn quality.

Two other studies have focused on the genetics of digital cushion. Iqbal et al. (2016) targeted specific genes and reported that lipogenic genes were consistently upregulated when cows were fed a higher energy diet. None of the 27 genes investigated by Iqbal et al. (2016) were candidate genes in the current study. Stambuk et al. (2020) discovered 27 SNP associated with DCT in Holstein cows across BTA14, BTA24, and BTA29, whereas the current study identified 19 new SNP across BTA3, BTA4, BTA7, BTA9, BTA14, BTA27, and the X chromosome associated with DCT in multiple breeds and cows and bulls. Both studies determined putative candidate genes related to bone remodeling and fat deposition. The gene annotated as affecting fat accumulation in Stambuk et al. (2020) was from the models on DCT of the average FM digit and average front foot, whereas the 2 genes related to fat in the current study were from models on DCT of the HL digit and average DCT of all measurements in Jersey. The genes that functioned in bone growth were from models on DCT of the FM digit and average front foot in Holstein and the HL digit and average hind foot in Jersey. Interestingly, this study is the only one to identify a gene related to epidermal keratinocyte function from the model on DCT of the average front foot in Holstein.

The average SNP heritability in the current study of DCT based on the 10 GWAS models with significant SNP was $0.58 \pm 0.17$. The genetic variation for Jersey cows and bulls (0.006) was less than that of Holstein cows and bulls (0.025), which could be due to the limited diversity of pedigrees and smaller sample size in the Jersey population from 2 farms in the current study. The heritability in this study for Holsteins, including cows and bulls, was greater than the $0.33 \pm$ 0.09 (classical narrow-sense heritability using variance components to estimate only additive genetic variance derived from univariate analysis) and $0.31 \pm 0.13$ (SNP heritability) estimated by Oikonomou et al. (2014) and Stambuk et al. (2020), respectively. The heritability for average DCT of cows was 0.43 and was similar to that of reported studies only using Holstein cows. The difference could be due to the methods of determining heritability (fitting variance component models with and without SNP data), population differences, and covariates included in the model. Recently, SánchezMolano et al. (2019) reported heritability, genetic variance, and environmental variance of $0.228,0.549$, and 1.854 , respectively. Possibly, the environmental variance in the current study did not affect the results as much for DCT as reported in Sánchez-Molano et al. (2019). Environmental conditions of the Holstein and Jersey farms, and of the bulls in particular, may have influenced the higher estimation of heritability for Holsteins in the current study.

The SNP heritability may have been overestimated due to inclusion of false-positive markers because of the smaller sample size and large numbers of SNP. The genetic relationship matrix based on the SNP and covariates (combinations of breed, sex, genotyping batch plate, age, BCS, withers height, and sacral height) were included in the SNP heritability calculation to account for population stratification, which may decrease the opportunity of false positives that might lead to an overestimation of heritability. Previous research determined heritability in Holstein cows, whereas this study calculated SNP heritability in data sets including both cows and bulls from Holstein and Jersey breeds. The 
average genetic variation in DCT in the 9 GWAS models with significant SNP and both sexes was $0.024 \mathrm{~cm}$, whereas the 1 GWAS model with significant SNP from the cow data set had a genetic variation of $0.009 \mathrm{~cm}$.

Only results evaluated on traits with additive inheritance can be included in traditional genomic evaluations (Cole et al., 2009; Aliloo et al., 2016). Five out of the 10 GWAS models with significant SNP were evaluated with additive inheritance, meaning the 8 markers from these models could be incorporated in genomic evaluations. BovineHD4100007739, BovineHD3000041411, and BovineHD3000041398 were determined to be associated with DCT in the combined data set; thus, these markers are universal and can be applied across Holsteins and Jerseys and both sexes. BovineHD2700001198, BovineHD2700001206, BovineHD2700001209, and BovineHD2700001220 could be incorporated in genomic evaluations for Holstein, whereas Hapmap41614-BTA-67626 could be used in Jersey genomic evaluations. The other 11 markers still have the opportunity to be used in breeding programs for marker-assisted selection against CHDL and lameness determined by visual locomotion score.

Results indicate that DCT is a polygenic complex trait influenced by genetic and environmental factors. Markers associated with DCT change depending on breed, sex, digit, and foot.

\section{CONCLUSIONS}

This study explored the effects of breed and sex on DCT both phenotypically and genetically. Digital cushion thickness in bulls, like cows, was influenced by breed, age, BCSG, and DGT. The phenotypic measure of average DCT of all digits, likely capturing the greatest degree of phenotypic variation, consistently provided significant genetic associations, regardless of breed or sex inclusion, suggesting this variable to be the optimal measure of DCT in future analysis. Genetic results discovered 19 novel genetic markers on BTA3, BTA4, BTA7, BTA9, BTA14, BTA27, and the X chromosome associated with DCT near biologically plausible genes. The 8 candidate genes highlighted were related to fat accumulation, bone development, and epidermal keratinocyte function. Candidate genes were breed specific but had similar functions, suggesting differential regulation of DCT within breeds. The exception was EFNA5, related to bone development, which was identified in both Holsteins and Jerseys. Eight markers on BTA3, BTA9, BTA27, and the X chromosome from additive GWAS models may be applied to genomic evaluations in the future to reduce CHDL and lameness. Research results refine the use of these markers for within-breed or across-breed genomic selection. It is easier to add markers to genomic evaluations associated with $\mathrm{DCT}$ on a farm that is already genotyping than to collect the physical measurements of the digital cushion due to the skill, time commitment, and equipment needed and the potential stress to the animals. Further studies on the biologically plausible candidate genes are needed to determine genetic variants within the genes and how they relate to DCT within Holstein or Jersey through gene regulation and expression.

\section{ACKNOWLEDGMENTS}

This research project was funded by the US Department of Agriculture National Institute of Food and Agriculture (USDA/NIFA, Washington, DC) Federal Formula Funds Hatch Project \#2015-16-117. The authors thank the farms, hoof trimmers, and Genex (Ithaca, NY), particularly Steve Tibbits and Jim Lilly, for their participation and accommodation during the study. The authors have stated no conflicts of interest.

\section{REFERENCES}

Aliloo, H., J. E. Pryce, O. González-Recio, B. G. Cocks, and B. J. Hayes. 2016. Accounting for dominance to improve genomic evaluations of dairy cows for fertility and milk production traits. Genet. Sel. Evol. 48:8. https://doi.org/10.1186/s12711-016-0186-0.

Bergsten, C., A. Brizzi, C. K. W. Mülling, and K. Nordlund. 2007. Genetic Selection and Conformation. Pages 141-154 in: Bovine Laminitis and Lameness: A hands-on approach. P. Greenough, ed. Elsevier, Edinburgh, UK. https://doi.org/10.1016/B978-0-7020 $-2780-2.50016-1$.

Bicalho, R. C., V. S. Machado, and L. S. Caixeta. 2009. Lameness in dairy cattle: A debilitating disease or a disease of debilitated cattle? A cross-sectional study of lameness prevalence and thickness of the digital cushion. J. Dairy Sci. 92:3175-3184. https://doi .org/10.3168/jds.2008-1827.

Cheng, D. D., S. Li, B. Zhu, T. Yuan, Q. Yang, and C. Fan. 2017. Downregulation of BZW2 inhibits osteosarcoma cell growth by inactivating the Akt/mTOR signaling pathway. Oncol. Rep. 38:2116-2122. https://doi.org/10.3892/or.2017.5890.

Cole, J. B., P. M. Van Raden, J. R. O'Connell, C. P. Van Tassell, T. S. Sonstegard, R. D. Schnabel, J. F. Taylor, and G. R. Wiggans. 2009. Distribution and location of genetic effects of dairy traits. J. Dairy Sci. 92:2931-2946. https://doi.org/10.3168/jds.2008-1762.

Edmonson, A. J., I. J. Lean, L. D. Weaver, T. Farver, and G. Webster. 1989. A body condition scoring chart for Holstein dairy cows. J. Dairy Sci. 72:68-78. https://doi.org/10.3168/jds.S0022 $-0302(89) 79081-0$.

Faccio, R., S. L. Teitelbaum, K. Fujikawa, J. Chappel, A. Zallone, V. L. Tybulewicz, F. P. Ross, and W. Swat. 2005. Vav3 regulates osteoclast function and bone mass. Nat. Med. 11:284-290. https:/ /doi.org/10.1038/nm1194.

Gard, J. A., D. R. Taylor, D. R. Wilhite, S. P. Rodning, M. L. Schnuelle, R. K. Sanders, R. J. Beyers, M. A. Edmondson, F. J. DeGraves, and E. van Santen. 2015. Effect of exercise and environmental terrain on development of the digital cushion and bony structures of the bovine foot. Am. J. Vet. Res. 76:246-252. https:/ /doi.org/10.2460/ajvr.76.3.246.

Hensel, J., A. Wetterwald, R. Temanni, I. Keller, C. Riether, G. van der Pluijm, M. G. Cecchini, and G. N. Thalmann. 2018. Osteolytic cancer cells induce vascular/axon guidance processes in the bone/ 
bone marrow stroma. Oncotarget 9:28877-28896. https://doi.org/ 10.18632/oncotarget.25608.

Heringstad, B., C. Egger-Danner, N. Charfeddine, J. E. Pryce, K. F. Stock, J. Kofler, A. M. Sogstad, M. Holzhauer, A. Fiedler, K. Müller, P. Nielsen, G. Thomas, N. Gengler, G. de Jong, C. Ødegård, F. Malchiodi, F. Miglior, M. Alsaaod, and J. B. Cole. 2018. Invited review: Genetics and claw health: Opportunities to enhance claw health by genetic selection. J. Dairy Sci. 101:4801-4821. https:// doi.org/10.3168/jds.2017-13531.

Holstein Association USA. 2019. Facts about Holstein cattle. Accessed May 3, 2019. http://www.holsteinusa.com/holstein_breed/ holstein101.html?tab=2\#TabbedPanels1.

Hou, K., K. S. Burch, A. Majumdar, H. Shi, N. Mancuso, Y. Wu, S. Sankararaman, and B. Pasaniuc. 2019. Accurate estimation of SNP-heritability from biobank-scale data irrespective of genetic architecture. (31358995). Nat. Genet. 51:1244-1251. https://doi .org/10.1038/s41588-019-0465-0.

Hsieh, J. C., R. C. Estess, I. Kaneko, G. K. Whitfield, P. W. Jurutka, and M. R. Haussler. 2014. Vitamin D receptor-mediated control of Soggy, Wise, and Hairless gene expression in keratinocytes. J. Endocrinol. 220:165-178. https://doi.org/10.1530/JOE-13-0212.

Iqbal, Z. M., H. Akbar, A. Hosseini, E. Bichi Ruspoli Forteguerri, J. S. Osorio, and J. J. Loor. 2016. Digital cushion fatty acid composition and lipid metabolism gene network expression in Holstein dairy cows fed a high-energy diet. PLoS One 11:e0159536. https:/ /doi.org/10.1371/journal.pone.0159536.

Kang, H. M., J. H. Sul, S. K. Service, N. A. Zaitlen, S. Y. Kong, N. B. Freimer, C. Sabatti, and E. Eskin. 2010. Variance component model to account for sample structure in genome-wide association studies. Nat. Genet. 42:348-354. https://doi.org/10.1038/ng.548.

Kang, H. M., N. A. Zaitlen, C. M. Wade, A. Kirby, D. Heckerman, M. J. Daly, and E. Eskin. 2008. Efficient control of population structure in model organism association mapping. Genetics 178:17091723. https://doi.org/10.1534/genetics.107.080101.

Korkalainen, M., E. Kallio, A. Olkku, K. Nelo, J. Ilvesaro, J. Tuukkanen, A. Mahonen, and M. Viluksela. 2009. Dioxins interfere with differentiation of osteoblasts and osteoclasts. Bone 44:1134-1142. https://doi.org/10.1016/j.bone.2009.02.019.

Kuang, M. J., F. Xing, D. Wang, L. Sun, J. Ma, and X. Ma. 2019. CircUSP45 inhibited osteogenesis in glucocorticoid-induced osteonecrosis of femoral head by sponging miR-127-5p through PTEN/ AKT signal pathway: Experimental studies. Biochem. Biophys. Res. Commun. 509:255-261. https://doi.org/10.1016/j.bbrc.2018 .12 .116 .

Lischer, C. J., P. Ossent, M. Räber, and H. Geyer. 2002. Suspensory structures and supporting tissues of the third phalanx of cows and their relevance to the development of typical sole ulcers (Rusterholz ulcers). Vet. Rec. 151:694-698. https://doi.org/10.1136/vr .151 .23 .694 .

Littell, R. C., P. R. Henry, and C. B. Ammerman. 1998. Statistical analysis of repeated measures data using SAS procedures. J. Anim. Sci. 76:1216-1231. https://doi.org/10.2527/1998.7641216x.

Machado, V. S., L. S. Caixeta, and R. C. Bicalho. 2011. Use of data collected at cessation of lactation to predict incidence of sole ulcers and white line disease during the subsequent lactation in dairy cows. Am. J. Vet. Res. 72:1338-1343. https://doi.org/10.2460/ajvr 72.10 .1338

Mülling, C. K., H. H. Bragulla, S. Reese, K. D. Budras, and W. Steinberg. 1999. How structures in bovine hoof epidermis are influenced by nutritional factors. Anat. Histol. Embryol. 28:103-108. https:/ /doi.org/10.1046/j.1439-0264.1999.00180.x.

Mülling, C. K. W., and P. R. Greenough. 2006. Applied physiopathology of the foot. In XXIV World Buiatrics Congress, Nice, France. World Association for Buiatrics, Paris, France. http://citeseerx .ist.psu.edu/viewdoc/download?doi=10.1.1.585.2700\&rep=rep1\& type $=$ pdf.

Murray, R. D., D. Y. Downham, M. J. Clarkson, W. B. Faull, J. W. Hughes, F. J. Manson, J. B. Merritt, W. B. Russell, J. E. Sutherst, and W. R. Ward. 1996. Epidemiology of lameness in dairy cattle: Description and analysis of foot lesions. Vet. Rec. 138:586-591. https://doi.org/10.1136/vr.138.24.586.
Newsome, R., M. J. Green, N. J. Bell, M. G. G. Chagunda, C. S. Mason, C. S. Rutland, C. J. Sturrock, H. R. Whay, and J. N. Huxley. 2016. Linking bone development on the caudal aspect of the distal phalanx with lameness during life. J. Dairy Sci. 99:4512-4525. https://doi.org/10.3168/jds.2015-10202.

Newsome, R. F., M. J. Green, N. J. Bell, N. J. Bollard, C. S. Mason, H. R. Whay, and J. N. Huxley. 2017a. A prospective cohort study of digital cushion and corium thickness. Part 1: Associations with body condition, lesion incidence, and proximity to calving. J. Dairy Sci. 100:4745-4758. https://doi.org/10.3168/jds.2016-12012.

Newsome, R. F., M. J. Green, N. J. Bell, N. J. Bollard, C. S. Mason, H. R. Whay, and J. N. Huxley. 2017b. A prospective cohort study of digital cushion and corium thickness. Part 2: Does thinning of the digital cushion and corium lead to lameness and claw horn disruption lesions? J. Dairy Sci. 100:4759-4771. https://doi.org/ $10.3168 /$ jds.2016-12013.

Oikonomou, G., G. Banos, V. Machado, L. Caixeta, and R. C. Bicalho. 2014. Genetic characterization of digital cushion thickness. J. Dairy Sci. 97:532-536. https://doi.org/10.3168/jds.2013-7212.

Oikonomou, G., N. B. Cook, and R. C. Bicalho. 2013. Sire predicted transmitting ability for conformation and yield traits and previous lactation incidence of foot lesions as risk factors for the incidence of foot lesions in Holstein cows. J. Dairy Sci. 96:3713-3722. https: //doi.org/10.3168/jds.2012-6308.

Plourde, M., M. Vohl, C. Bellis, M. Carless, T. Dyer, G. Dolley, A. Marette, J. Després, C. Bouchard, J. Blangero, and L. Pérusse. 2013. A variant in the LRRFIP1 gene is associated with adiposity and inflammation. Obesity (Silver Spring) 21:185-192. https://doi .org/10.1002/oby.20242.

Purcell, S., B. Neale, K. Todd-Brown, L. Thomas, M. A. Ferreira, D. Bender, J. Maller, P. Sklar, P. I. de Bakker, M. J. Daly, and P. C. Sham. 2007. PLINK: A tool set for whole-genome association and population-based linkage analyses. Am. J. Hum. Genet. 81:559-575. https://doi.org/10.1086/519795.

Räber, M., C. Lischer, H. Geyer, and P. Ossent. 2004. The bovine digital cushion-A descriptive anatomical study. Vet. J. 167:258-264. https://doi.org/10.1016/S1090-0233(03)00053-4.

Sánchez-Molano, E., V. Bay, R. F. Smith, G. Oikonomou, and G. Banos. 2019. Quantitative trait loci mapping for lameness associated phenotypes in Holstein-Friesian dairy cattle. Front. Genet. 10:926. https://doi.org/10.3389/fgene.2019.00926.

Shearer, J. K., P. J. Plummer, and J. A. Schleining. 2015. Perspectives on the treatment of claw lesions in cattle. Vet. Med. (Auckl.) 6:273-292. https://doi.org/10.2147/VMRR.S62071.

Sprecher, D. J., D. E. Hostetler, and J. B. Kaneene. 1997. A lameness scoring system that uses posture and gait to predict dairy cattle reproductive performance. Theriogenology 47:1179-1187. https:// doi.org/10.1016/S0093-691X(97)00098-8.

Stambuk, C. R., J. A. A. McArt, B. C. Bicalho, A. M. Miles, and H. J. Huson. 2019. A longitudinal study of digital cushion thickness and its function as a predictor for compromised locomotion and hoof lesions in Holstein cows. Transl. Anim. Sci. 3:74-83. https:// doi.org/10.1093/tas/txy107.

Stambuk, C. R., E. A. Staiger, A. Nazari-Ghadikolaei, B. J. Heins, and H. J. Huson. 2020. Phenotypic characterization and genome-wide association studies of digital cushion thickness in Holstein cows. J. Dairy Sci. 103:3289-3303. https://doi.org/10.3168/jds.2019-17409.

Toussaint Raven, E. 1989. Cattle Footcare and Claw Trimming. Farming Press, Ipswich, UK.

van der Tol, P. P., J. H. Metz, E. N. Noordhuizen-Stassen, W. Back, C. R. Braam, and W. A. Weijs. 2002. The pressure distribution under the bovine claw during square standing on a flat substrate. J. Dairy Sci. 85:1476-1481. https://doi.org/10.3168/jds.S0022 -0302(02)74216-1.

Visscher, P. M., G. Hemani, A. A. E. Vinkhuyzen, G. B. Chen, S. H. Lee, N. R. Wray, M. E. Goddard, and J. Yang. 2014. Statistical power to detect genetic (co)variance of complex traits using SNP data in unrelated samples. PLoS Genet. 10:e1004269. https://doi .org/10.1371/journal.pgen.1004269.

Wang, X., C. Xue, X. Wang, H. Liu, Y. Xu, R. Zhao, Z. Jiang, M. V. Dodson, and J. Chen. 2009. Differential display of expressed genes 
reveals a novel function of SFRS18 in regulation of intramuscular fat deposition. Int. J. Biol. Sci. 5:28-33. https://doi.org/10.7150/ ijbs.5.28.

Yang, J., S. Hong Lee, M. L. Goddard, and P. M. Visscher. 2011 GCTA: A tool for genome-wide complex trait analysis. Am. J. Hum. Genet. 88:76-82. https://doi.org/10.1016/j.ajhg.2010.11 .011.

Zaitlen, N., and P. Kraft. 2012. Heritability in the genome-wide association era. Hum. Genet. 131:1655-1664. https://doi.org/10.1007/ s00439-012-1199-6.

\section{ORCIDS}

C. R. Stambuk @ https://orcid.org/0000-0003-0652-8669

E. A. Staiger $\odot$ https://orcid.org/0000-0002-5677-0798

B. J. Heins 누 https://orcid.org/0000-0003-2186-9082

H. J. Huson ๑ https://orcid.org/0000-0001-8299-0447

\section{APPENDIX}

(a)

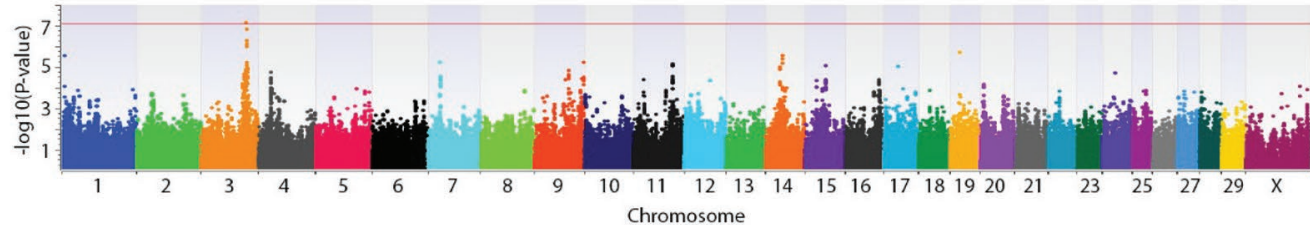

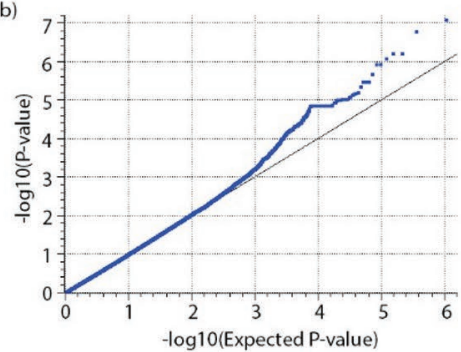

Figure A1. (a) Manhattan plot and (b) quantile-quantile plot for average digital cushion thickness of all measurements for the cow data set including Holstein $(\mathrm{n}=432)$ and Jersey $(\mathrm{n}=168)$ breeds. The red horizontal line indicates the Bonferroni adjusted $P$-value threshold of 0.05 .

(a)

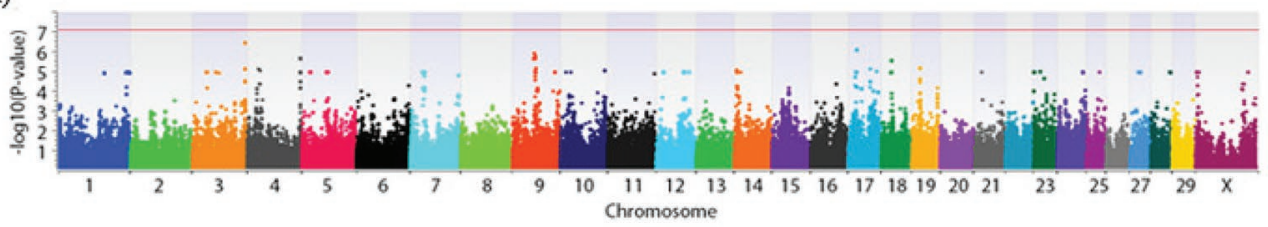

(b)

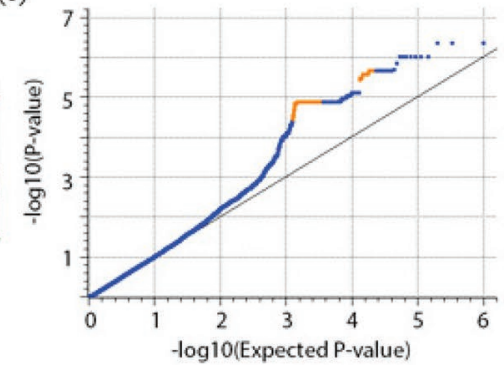

Figure A2. (a) Manhattan plot and (b) quantile-quantile plot for digital cushion thickness of the hind lateral digit for the Jersey cow data set. The blue squares are markers that had a false discovery rate $P$-value $\geq 0.05$ and the orange squares are markers that had a false discovery rate $P$-value $<0.05$. The red horizontal line indicates the Bonferroni-adjusted $P$-value threshold of 0.05 . 
(a)

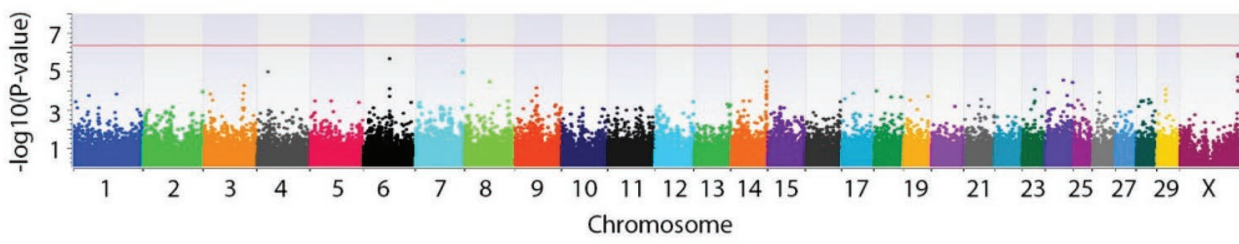

(c)

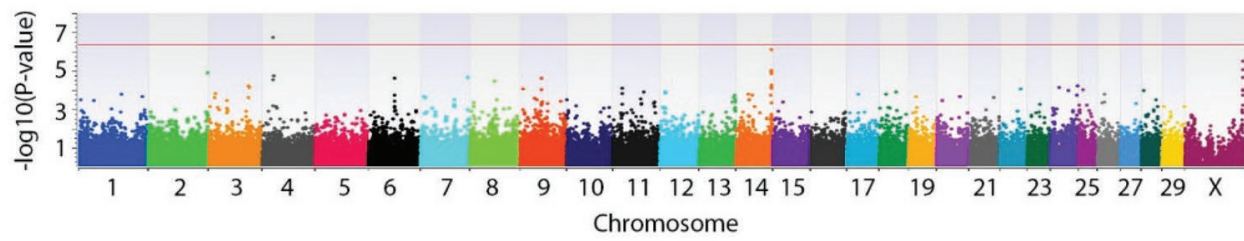

(e)

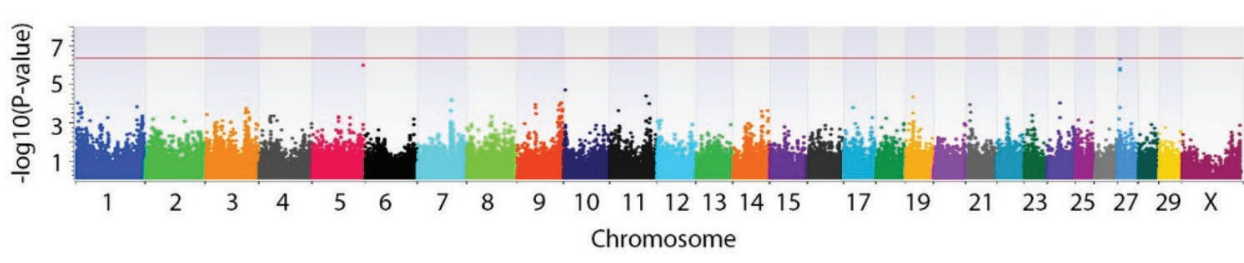

(g)

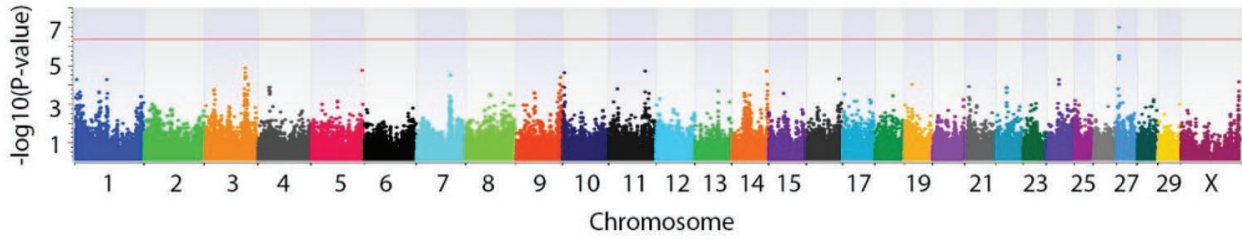

(b)

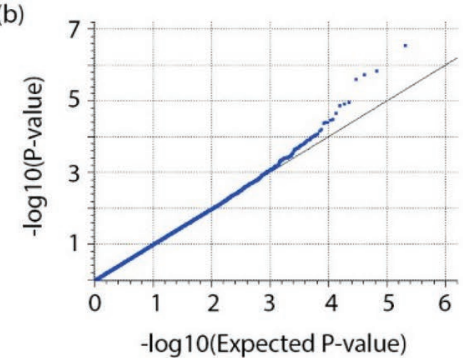

(d)

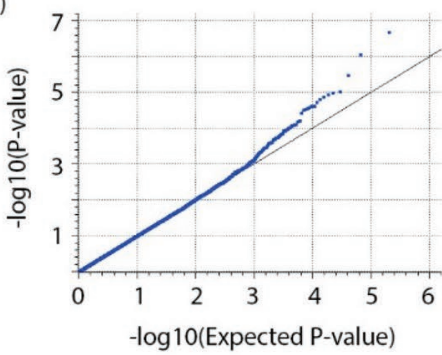

(f)

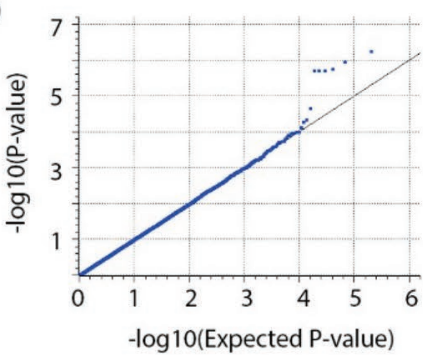

(h)

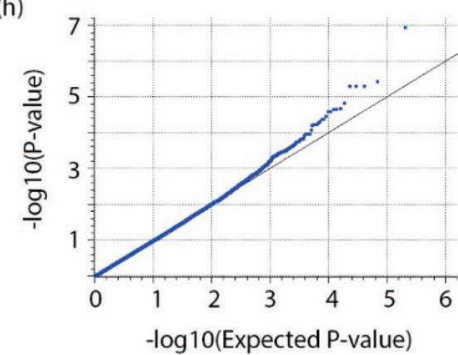

Figure A3. Manhattan plots and quantile-quantile plots for digital cushion thickness by (a, b) front medial digit, (c, d) average of the digits of the front foot, $(\mathrm{e}, \mathrm{f})$ average of the digits of the hind foot, and $(\mathrm{g}, \mathrm{h})$ average of all measurements for the Holstein data set including cows (n $=431)$ and bulls $(\mathrm{n}=23)$. The red horizontal line indicates the Bonferroni-adjusted $P$-value threshold of 0.05 . 
(a)

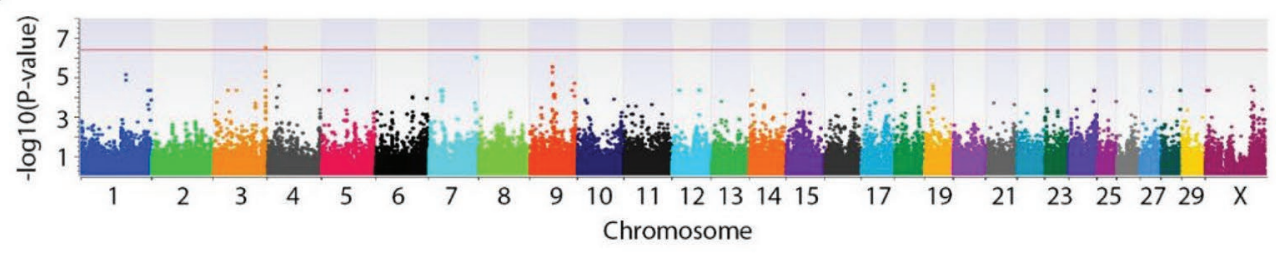

(c)

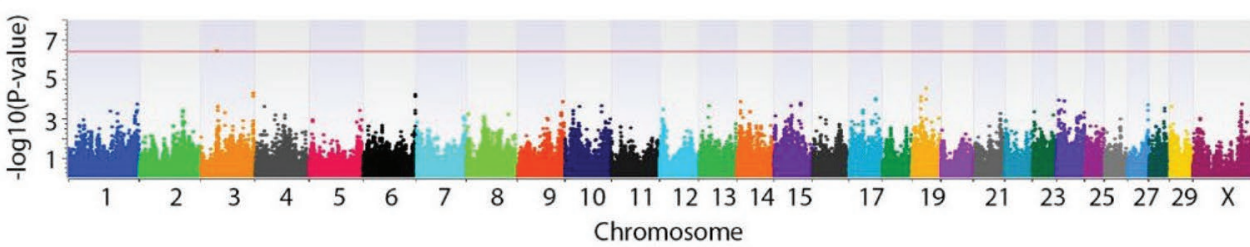

(e)

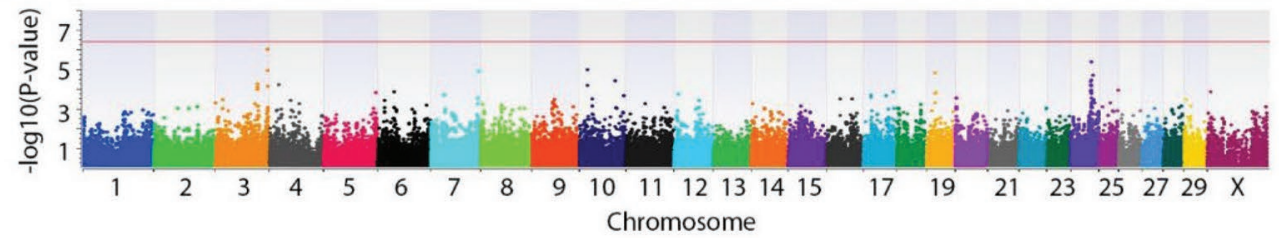

(b)

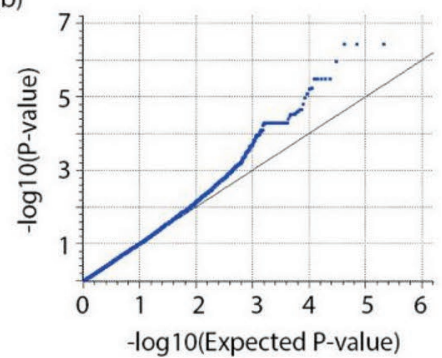

(d)

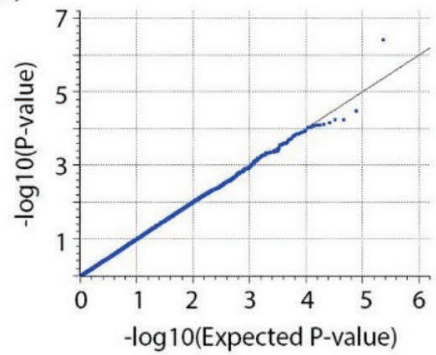

(f)

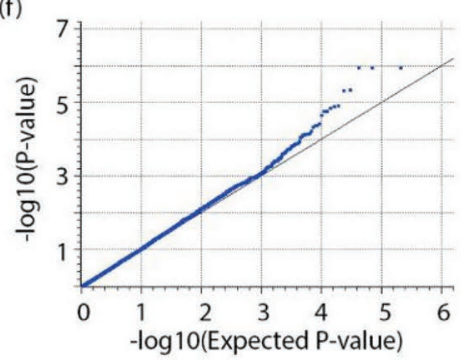

Figure A4. Manhattan plots and quantile-quantile plots for digital cushion thickness by (a, b) hind lateral digit, (c, d) average of the digits of the hind foot, and (e, f) average of all measurements for the Jersey data set including cows $(\mathrm{n}=168)$ and bulls $(\mathrm{n}=8)$. The red horizontal line indicates the Bonferroni-adjusted $P$-value threshold of 0.05 .

(a)

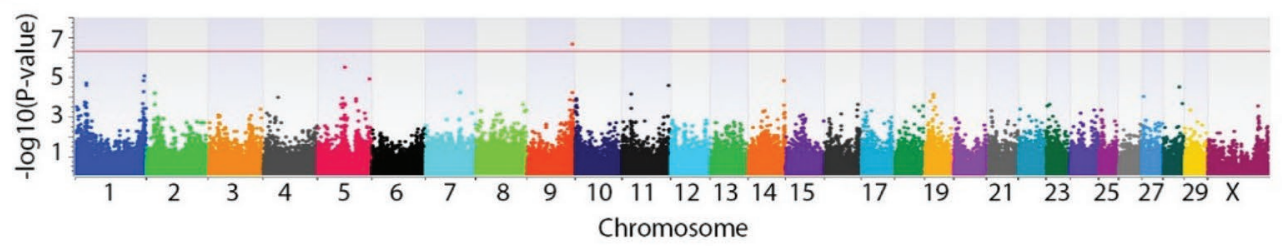

(d)

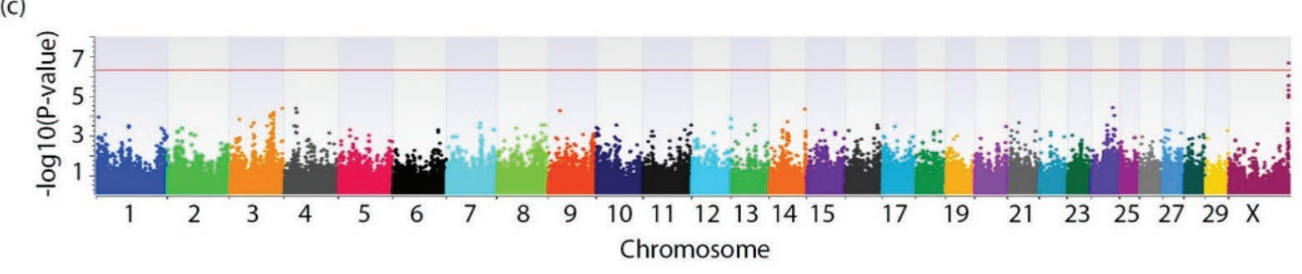

(b)
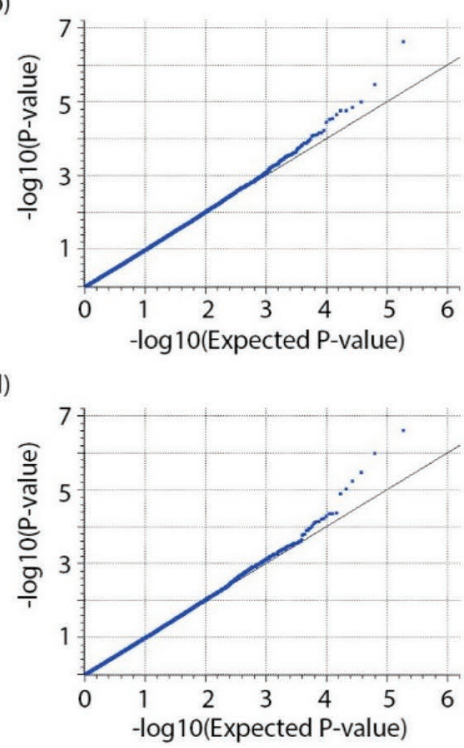

Figure A5. Manhattan plots and quantile-quantile plots for digital cushion thickness by (a, b) hind lateral digit and (c, d) average of the digits of the front foot for the combined data set including Holstein cows $(\mathrm{n}=431)$, Jersey cows $(\mathrm{n}=168)$, Holstein bulls $(\mathrm{n}=23)$, and Jersey bulls $(\mathrm{n}=8)$. The red horizontal line indicates the Bonferroni-adjusted $P$-value threshold of 0.05 . 
(a)

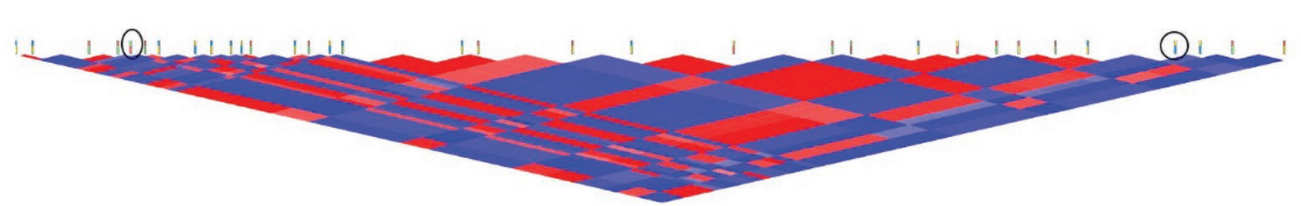

(b)

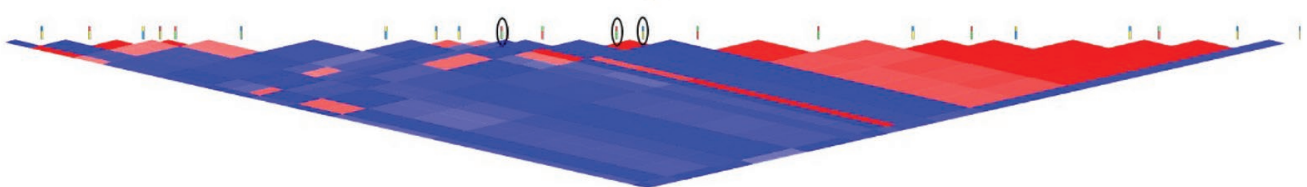

(c)

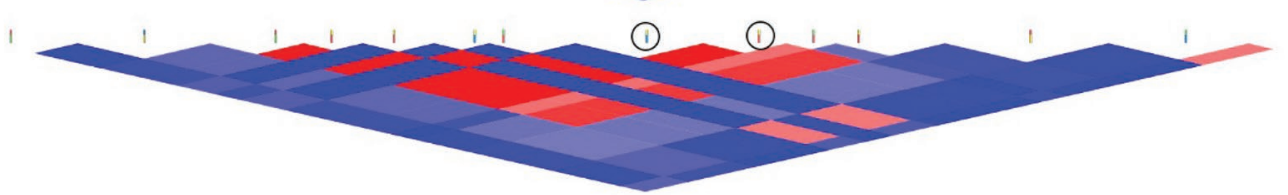

(d)

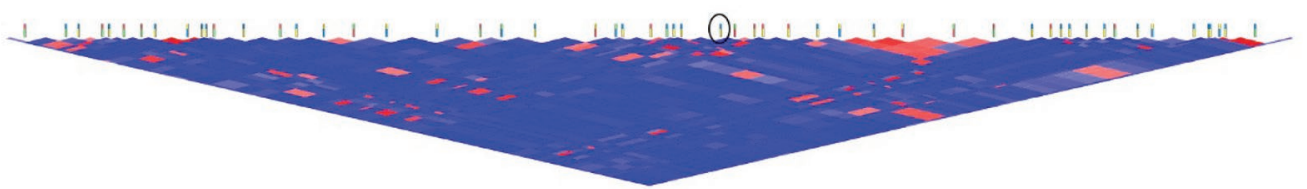

(e)

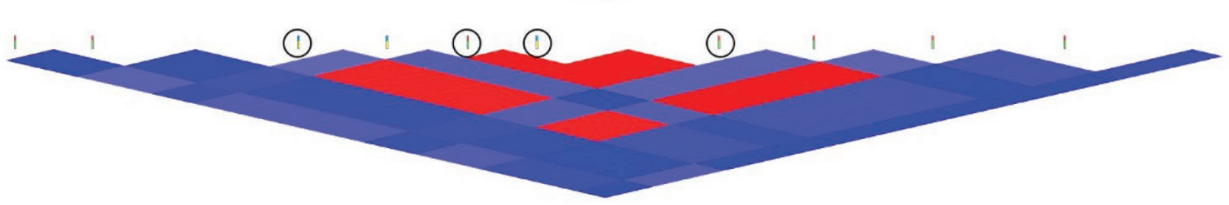

(f)

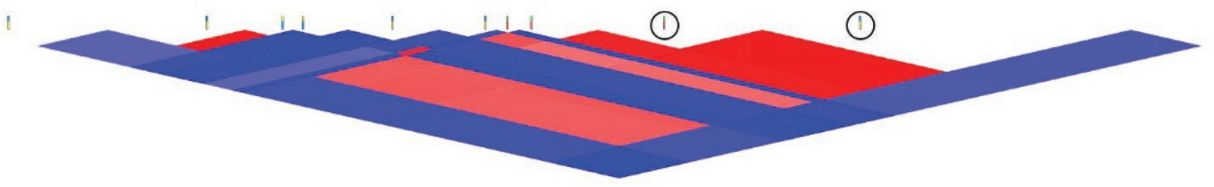

Figure A6. Linkage disequilibrium plots for blocks (a) BTA3:95849910-95930841, (b) BTA3:117091875-117135023, (c) BTA9: 50277681-50370897, (d) BTA14:80044488-80662041, (e) BTA27:4672201-4770314, and (f) chrX:132758690-132859284 with R ${ }^{2}>0.80$ containing markers that passed Bonferroni adjusted significance threshold or false discovery rate. The circles correspond to the location of the 14 significant markers. The colors represent correlation between 2 alleles with blue shading for $\mathrm{R}^{2}<0.50$ and red shading for $\mathrm{R}^{2}>0.50$, with the shading darkening as the value reaches the extremes of 0 and 1 . 
(a)

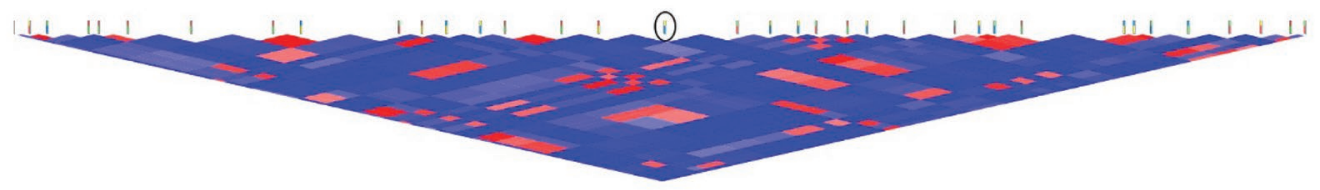

(b)

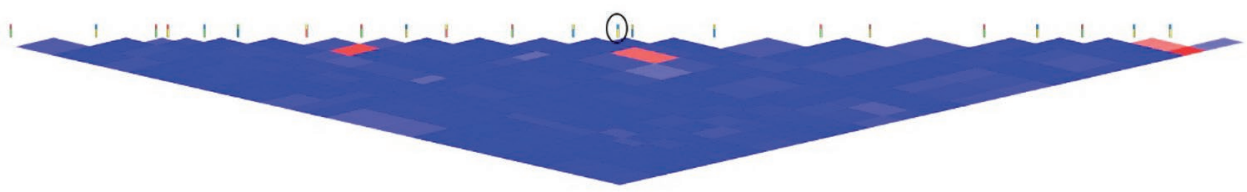

(c)

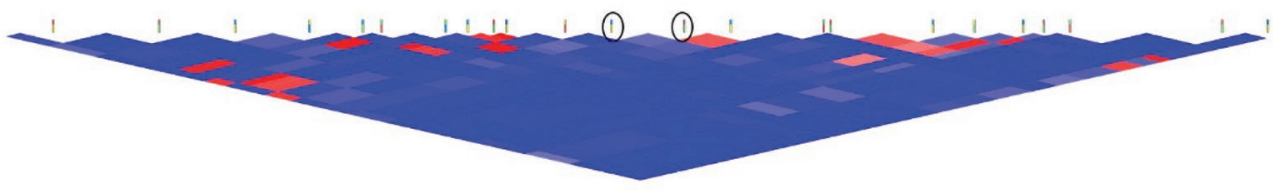

(d)

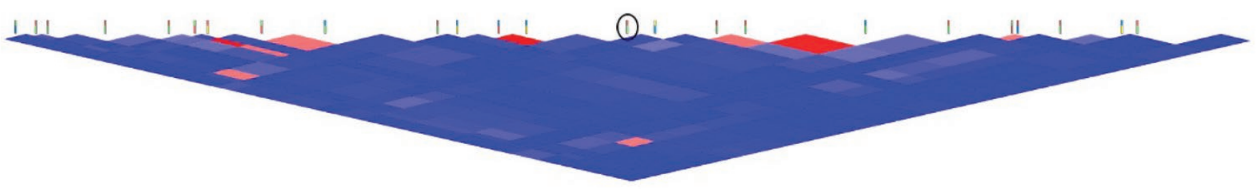

Figure A7. Linkage disequilibrium plots for (a) BTA3:36159480, (b) BTA4:25367830, (c) BTA7:106853053 and BTA7:106870956, and (d) BTA9:99886339 that passed the Bonferroni-adjusted significance threshold or false discovery rate and were not in blocks with $\mathrm{R}^{2}>0.80$. The circles correspond to the location of the 5 significant markers. The colors represent correlation between 2 alleles with blue shading for $\mathrm{R}^{2}<0.50$ and red shading for $\mathrm{R}^{2}>0.50$, with the shading darkening as the value reaches the extremes of 0 and 1 . 